EPJ Web of Conferences 12, 04003 (2011)

DOI: $10.1051 /$ epjconf/20111204003

(C) Owned by the authors, published by EDP Sciences, 2011

\title{
The electrochemistry of carbon steel in simulated concrete pore water in boom clay repository environments
}

\author{
D.D. Macdonald, A. Saleh, S.K. Lee, O. Azizi, O. Rosas-Camacho, \\ A. Al-Marzooqi and M. Taylor \\ Center for Electrochemical Sciences and Technology, Department of Materials Sciences and \\ Engineering, Pennsylvania State University, University Park, PA 16802, USA
}

\begin{abstract}
The prediction of corrosion damage of canisters to experimentally inaccessible times is vitally important in assessing various concepts for the disposal of High Level Nuclear Waste. Such prediction can only be made using deterministic models, whose predictions are constrained by the time-invariant natural laws. In this paper, we describe the measurement of experimental electrochemical data that will allow the prediction of damage to the carbon steel overpack of the super container in Belgium's proposed Boom Clay repository by using the Point Defect Model (PDM). PDM parameter values are obtained by optimizing the model on experimental, wide-band electrochemical impedance spectroscopy data.
\end{abstract}

\section{INTRODUCTION}

The super container concept for the disposal of high level nuclear waste (HLNW) in Belgium's proposed Boom Clay repository comprises a carbon steel overpack containing the waste and an outer, stainless steel liner that defines an annulus containing a cementitious material (similar to Portland cement-based concrete) [1]. Both the outer surface of the overpack and the inner surface of the liner will be in contact with concrete pore water, which for our current purposes is defined as saturated $\mathrm{Ca}(\mathrm{OH})_{2}+\mathrm{NaOH}$ to yield a pH at $25^{\circ} \mathrm{C}$ of 13.5 . It is recognized, however, that if (or when) the stainless steel liner is breached; dissolved sulfur species formed by oxidation of pyrite $\left(\mathrm{FeS}_{2}\right)$ in the near field environment may penetrate into the annulus and cause accelerated corrosion of the carbon steel. Chloride ion is present in both the concrete and Boom clay environments, to an extent that it, too, must be considered a deleterious species that is capable of inducing passivity breakdown on both carbon steel and stainless steel if the potential is sufficiently high [2]. Furthermore, during the initial period of waste disposal, depending upon the type of waste contained (reprocessed waste, non-reprocessed waste), the initial temperature will be in excess of $100^{\circ} \mathrm{C}$ and will decay over about 300 years to the ambient temperature of about $22{ }^{\circ} \mathrm{C}$. The calculations presented elsewhere [1] predict that oxygen in the annulus will be consumed quickly by corrosion and that the annulus environment will become essentially anoxic after a few years, after which water reduction, rather than oxygen reduction, becomes the principal cathodic reaction. As the oxygen concentration decreases, the hydrogen concentration increases, and the temperature decreases, the corrosion potential is predicted to increase, with the fall in temperature dominating at least over the first 300 years. Once the temperature has decayed to ambient and the annulus is saturated with hydrogen, the corrosion potential is predicted to be about $-0.75 \mathrm{~V}_{\text {she }}$.

In the present paper, we report the corrosion behavior of carbon steel during the initial oxic period, when the potential is expected to be between $-0.4 \mathrm{~V}$ and $+0.3 \mathrm{~V}_{\text {she }}$. We have been particularly concerned with measuring the steady state value of the passive current density and electrochemical impedance spectroscopy data for carbon steel in simulated concrete pore water $\left(\mathrm{Ca}(\mathrm{OH})_{2}+\mathrm{NaOH}\right.$

This is an Open Access article distributed under the terms of the Creative Commons Attribution-Noncommercial License 3.0, which permits unrestricted use, distribution, and reproduction in any noncommercial medium, provided the original work is properly cited. 


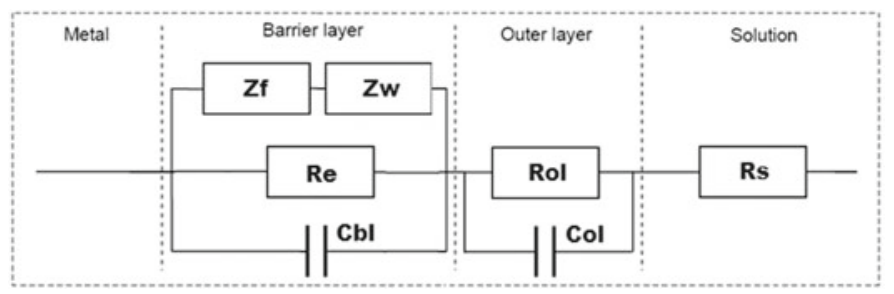

Figure 1. Electrical equivalent circuit used to model the impedance properties of passive iron. $Z_{\mathrm{f}}=$ faradaic impedance, $\mathrm{Z}_{\mathrm{W}}=$ Warburg impedance for defect transport across the barrier layer, $\mathrm{C}_{\mathrm{bl}}=$ capacitance in parallel with the barrier layer, $\mathrm{R}_{\mathrm{ol}}$ and $\mathrm{C}_{\mathrm{ol}}$ are the specific resistance and the capacitance, respectively, of the outer layer, and $R_{s}$ is the uncompensated resistance between the surface of the outer layer and the tip of the Luggin probe of the reference electrode.

to yield a pH at $25^{\circ} \mathrm{C}$ of 13.5 ) containing $\mathrm{Cl}^{-}, \mathrm{S}^{2-}$, and $\mathrm{S}_{2} \mathrm{O}_{3}^{2-}$ or mixtures of these species at temperatures ranging from $25^{\circ} \mathrm{C}$ to $80^{\circ} \mathrm{C}$. Additionally, on the basis of the Point Defect Model [2-4], we have developed models for the impedance of carbon steel from which we may extract values for the PDM parameters that may be used in the model for predicting the corrosion behavior over the long term (thousands of years). Space does not permit a detailed discussion of these models here and the reader is referred to the literature for details [2]. Our current work is extending these measurements to anoxic conditions, where the corrosion potential is predicted to be much lower $(-0.75 \mathrm{Vshe})$ and the temperature is predicted to be near ambient.

\section{IMPEDANCE MODEL}

The model developed in this work to interpret the impedance data is based upon the Point Defect Model (PDM) and incorporates elements of our previous work [3-6], Figure 1. Briefly, we have taken the total differential of the expression for the passive current density under non-steady state conditions in terms of the independent variables [voltage, barrier layer thickness, and concentration of metal interstitials at the barrier layer/solution (outer layer) interface (see Figure 2)] and we assume that these independent variables and the passive current density undergo sinusoidal variations with time. Taking the ratio of the vector current to the vector voltage defines the faradaic admittance, the inverse of which is the faradaic impedance. This impedance was then combined with the parallel capacitance for the barrier layer and the parallel resistance due to the transfer of electronic charge carriers (electrons and holes) across the barrier layer; this combination being in series with a parallel combination of a resistance and a capacitance representing the properties of the outer layer (Figure 1). In this analysis, we assume that $\mathrm{R}_{e}$ is effectively infinite and that the rate constants for the reactions at the metal/barrier layer and the barrier layer/outer layer (Figure 1) are corrected for the IR potential drop across the outer layer.

The expression for the faradaic admittance is developed as [3-6]

$$
Y_{f}=\frac{4 F\left(a_{1} k_{1}+a_{2} k_{2}\right)}{S_{0}}+\frac{4 F\left(b_{1} k_{1}+b_{2} k_{2}\right)}{S_{0}} \frac{\Delta L_{b l}}{\Delta V}
$$

where $S_{0}=1+4 F\left(a_{1} k_{1}+a_{2} k_{2}\right) R_{o l}$. The derivation of $\Delta L_{b l} / \Delta V$ is as follows. Firstly, we write the mass balance condition for the barrier layer as:

$$
\frac{d L_{b l}}{d t}=\Omega \cdot k_{2}-\Omega \cdot k_{5}\left(C_{H^{+}}^{B O I}\right)^{n}
$$

where $\Omega$ is the volume per mole of cations in the barrier layer, $C_{H^{+}}^{B O I}$ is the concentration of hydrogen ion at the barrier layer/outer layer interface (assumed to be a constant), and $n$ is the kinetic order of the film dissolution reaction with respect to the concentration of hydrogen ion. Taking the total 


$$
\begin{aligned}
& \text { Metal } \left.\mid \text { Barrier Layer (MO } \boldsymbol{M O}_{\chi / 2}\right) \mid \text { Solution } \\
& \begin{array}{ll}
\text { (1) } m+V_{M}^{\chi^{\prime}} \stackrel{k_{1}}{\longrightarrow} M_{M}+v_{m}+\chi e^{\prime} & \text { (4) } M_{M} \stackrel{k_{4}}{\longrightarrow} M^{\delta+}(a q)+V_{M}^{\chi^{\prime}}+(\delta-\chi) e^{\prime} \\
\text { (2) } m \stackrel{k_{2}}{\longrightarrow} M_{i}^{\chi+}+v_{m}+\chi e^{\prime} & \text { (5) } M_{i}^{\chi+} \stackrel{k_{5}}{\longrightarrow} M^{\delta+}(a q)+(\delta-\chi) e^{\prime}
\end{array} \\
& \begin{array}{ll}
\text { (3) } m \stackrel{k_{3}}{\longrightarrow} M_{M}+\left(\frac{\chi}{2}\right) V_{o}+\chi e^{\prime} & \text { (6) } V_{O}^{\ddot{O}}+H_{2} O \stackrel{k_{6}}{\longrightarrow} O_{O}+2 H^{+} \\
\mid & \text {(7) } M O_{\chi / 2}+\chi H^{+} \stackrel{k_{7}}{\longrightarrow} M^{\delta+}+\frac{\chi}{2} H_{2} O+(\delta-\chi) e^{\prime}
\end{array}
\end{aligned}
$$

Figure 2. Summary of the defect generation and annihilation reactions envisioned at the interfaces of the barrier oxide layer on a metal. $V_{M}^{\chi^{\prime}} \equiv$ cation vacancy, $v_{m} \equiv$ vacancy in the metal substrate, $M_{i}^{\chi+} \equiv$ cation interstitial, $V_{O} \equiv$ oxygen (anion) vacancy, $M^{\delta+}(a q) \equiv$ cation in outer layer/solution interface, $M_{M} \equiv$ cation in cation site on the metal sub lattice, $O_{O} \equiv$ oxide ion in anion site on the oxygen sub lattice, $M O_{\chi / 2} \equiv$ stoichiometric barrier layer oxide. Note that Reactions 1, 2, 4, 5 and 6 are lattice conservative processes (they do not result in the movement of the interface) whereas Reaction 3 and 7 are non-conservative [5].

differential as:

$$
\begin{aligned}
\frac{d \delta L_{b l}}{d t} & =j \omega \cdot \Delta L_{b l} \cdot e^{j \cdot \omega \cdot t} \\
& =\Omega \cdot\left(a_{2} k_{2} \cdot \delta V+b_{2} k_{2} \cdot \delta L_{b l}-a_{2} k_{2} R_{o l} \delta I\right)
\end{aligned}
$$

we find that

$$
\frac{\Delta L_{b l}}{\Delta V}=\frac{\Omega \cdot a_{2} k_{2}}{j \omega-\Omega \cdot b_{2} k_{2}}-\frac{\Omega \cdot a_{2} k_{2} R_{o l}}{j \omega-\Omega \cdot b_{2} k_{2}} \cdot Y_{f}
$$

which represents the relaxation in the thickness of the barrier layer upon imposition of the sinusoidal voltage perturbation. Note that it is a complex number containing both amplitude and phase information. At high frequencies $(\omega>10 \mathrm{rad} / \mathrm{s})$, it is found that $\Delta L / \Delta \mathrm{V} \approx 0$, so that the relaxation in barrier layer thickness is important only at very low frequencies.

The analysis involved optimization of the above model on the experimental impedance data to yield values for various model parameters [standard rate constants and transfer coefficients for the interfacial reactions (Figure 2), electric field strength, polarizability of the bl/ol interface, and other important model parameters]. Typical parameter values that are obtained by optimization are given in Table 1 . Data of these type allow us to calculate the properties of passive iron, including film thickness and passive current density, over a wide range of conditions.

The validity of the optimization procedure can be judged by the fact that the electric field strength, the standard rate constants and the transfer coefficients, the polarizability of the $\mathrm{bl} / \mathrm{ol}$ interface, amongst other parameters, should be independent of potential. They are generally found to be so. Later in this paper we show a comparison between the measured impedance as a function of frequency and that calculated from the parameter values of the type shown in Table 1.

\section{EXPERIMENTAL}

All experiments have been carried out in a typical three electrode electrochemical cell utilizing a saturated $\mathrm{Ca}(\mathrm{OH})_{2}$ solution with addition of sufficient sodium hydroxide to bring the $\mathrm{pH}$ up to 13.5 at $25^{\circ} \mathrm{C}$, which simulates the concrete pore electrolyte. A rod of carbon steel with an exposed area of $7.15 \mathrm{~cm}^{2}$ was used as the working electrode. The exposed surface of the working electrode was polished with $\mathrm{SiC}$ paper from 600 to 2400 grit and then polished with diamond paste to $1 \mathrm{MMe}$ and 
Table 1. Typical parameters values obtained by the optimization of the PDM model on experimental impedance data for iron in sat. $\mathrm{Ca}(\mathrm{OH})_{2}+\mathrm{NaOH}, \mathrm{pH}=13.5, \mathrm{E}=-0.200 \mathrm{~V}$ (vs. $\mathrm{Hg} / \mathrm{HgO}, 2 \mathrm{M} \mathrm{NaOH}$ ), and $\mathrm{T}=80^{\circ} \mathrm{C}$.

\begin{tabular}{|l|c|c|c|c|}
\hline Time (days) & 56 & 91 & 176 & 279 \\
\hline $\mathrm{T}(\mathrm{K})$ & 353 & 353 & 353 & 353 \\
\hline Potenial $(\mathrm{V}$ vs. Hg/HgO, 2M NaOH) & -0.2 & -0.2 & -0.2 & -0.2 \\
\hline Current $(\mathrm{A})$ & $7.84 \mathrm{E}-07$ & $7.34 \mathrm{E}-07$ & $4.97 \mathrm{E}-07$ & $2.76 \mathrm{E}-07$ \\
\hline Barrier Layer Thickness (cm) & $8.88 \mathrm{E}-07$ & $1.04 \mathrm{E}-06$ & $6.72 \mathrm{E}-07$ & $1.64 \mathrm{E}-06$ \\
\hline $\mathrm{R}_{\mathrm{e}}($ ohm cm2) & $1.00 \mathrm{E}+17$ & $1.00 \mathrm{E}+17$ & $1.00 \mathrm{E}+17$ & $1.00 \mathrm{E}+17$ \\
\hline $\mathrm{R}_{\mathrm{ol}}($ ohm cm2) & 23682 & 25886 & 21450 & 19507 \\
\hline $\mathrm{C}_{\mathrm{bl}}(\mathrm{F})$ & 0.00182 & 0.00168 & 0.00117 & 0.00139 \\
\hline $\mathrm{C}_{\mathrm{ol}}(\mathrm{F})$ & 0.0002 & 0.00025 & 0.00023 & 0.000366 \\
\hline $\mathrm{n}$ & 0.78 & 0.82 & 0.94 & 0.84 \\
\hline oxidation state in barrier layer $(\mathrm{c})$ & 2 & 2 & 2 & 2 \\
\hline oxidation state in solution $(\mathrm{G})$ & 3 & 3 & 3 & 3 \\
\hline Electric field 8 (V/cm) & $5.00 \mathrm{E}+05$ & $5.00 \mathrm{E}+05$ & $5.00 \mathrm{E}+05$ & $5.00 \mathrm{E}+05$ \\
\hline Warburg Coefficient & 7201.7 & 5094.1 & 7562.8 & 4066.6 \\
\hline polarizability (a) & 0.53 & 0.26 & 0.088 & 0.14 \\
\hline transfer coeff reaction 1 (a1) & 0.022 & 0.11 & 0.14 & 0.07 \\
\hline transfer coeff reaction 2 (a2) & 0.918 & 0.71 & 0.92 & 0.48 \\
\hline transfer coeff reaction 3 (a3) & 0.81 & 0.93 & 0.49 & 0.56 \\
\hline transfer coeff reaction 5 (a5) & 0.44 & 0.52 & 0.46 & 0.41 \\
\hline $\mathrm{k}_{1}^{\mathrm{o}}(1 / \mathrm{s})$ & $1.46 \mathrm{E}-06$ & $1.28 \mathrm{E}-06$ & $1.11 \mathrm{E}-06$ & $1.05 \mathrm{E}-06$ \\
\hline $\mathrm{k}_{2}^{\mathrm{o}}(1 / \mathrm{s})$ & $1.08 \mathrm{E}-10$ & $9.43 \mathrm{E}-11$ & $1.78 \mathrm{E}-10$ & $8.61 \mathrm{E}-11$ \\
\hline $\mathrm{k}_{3}^{\mathrm{o}}(1 / \mathrm{s}$ mol) & $1.16 \mathrm{E}-05$ & $8.33 \mathrm{E}-06$ & $7.67 \mathrm{E}-06$ & $1.59 \mathrm{E}-05$ \\
\hline $\mathrm{k}_{5}^{\mathrm{o}}(1 / \mathrm{s})$ & $8.55 \mathrm{E}-11$ & $1.19 \mathrm{E}-10$ & $9.90 \mathrm{E}-11$ & $8.20 \mathrm{E}-11$ \\
\hline $\mathrm{k} 1(1 / \mathrm{s})$ & $6.62 \mathrm{E}-07$ & $9.24 \mathrm{E}-09$ & $8.58 \mathrm{E}-09$ & $1.06 \mathrm{E}-08$ \\
\hline $\mathrm{k} 2(1 / \mathrm{s})$ & $5.06 \mathrm{E}-25$ & $1.42 \mathrm{E}-24$ & $2.37 \mathrm{E}-24$ & $1.76 \mathrm{E}-24$ \\
\hline $\mathrm{k} 3(1 / \mathrm{s}$ mol) & $5.30 \mathrm{E}-07$ & $1.46 \mathrm{E}-06$ & $5.69 \mathrm{E}-06$ & $9.36 \mathrm{E}-06$ \\
\hline $\mathrm{k} 5(1 / \mathrm{s})$ & $1.60 \mathrm{E}-11$ & $4.50 \mathrm{E}-11$ & $7.48 \mathrm{E}-11$ & $5.57 \mathrm{E}-11$ \\
\hline goodness-of-fit $(\mathrm{R} 2) \mathrm{Z}$ & 0.99644 & 0.99581 & 0.9956 & 0.9948 \\
\hline goodness-of-fit $(\mathrm{R} 2) \mathrm{Z}^{\prime \prime}$ & 0.99865 & 0.99841 & 0.99886 & 0.99851 \\
\hline
\end{tabular}

then finally polished with colloidal silica/alumina suspension down to $0.05 \mu \mathrm{m}$. A mercury/mercury oxide $(\mathrm{Hg} / \mathrm{HgO})$ in $2 \mathrm{M} \mathrm{NaOH}(0.112 \mathrm{~V}$ vs SHE$)$ was used as reference electrode and connected to the cell via a Lugging probe. Nickel gauze, 40 mesh of large surface area was used as the counter electrode. The test temperature was $80^{\circ} \mathrm{C}$ and the polarization experiment lasted for up to one year (343 days). For the long term experiments, the electrochemical cell was powered by an EG\&G Model 363 potentiostat/galvanostat and the impedance measurement were carried out using Gamry potentiostat/galvanostat incorporating a frequency response analyzer (FRA), while a Solartron 1286 potentiostat/galvanostat coupled with Solartron 1250 frequency response analyzer was used to conduct the short term experiments.

Six cells were operated simultaneously for the long term experiment in simulated concrete pore water under anoxic conditions, each with a separate potentiostat. Experiments included those at open circuit potential and under constant potential control. Because of the lack of suitable recording systems, current (potentiostatic polarization) and potential (open circuit experiment) were recorded manually on a daily basis. The electrochemical impedance (EIS) measurements were conducting weekly and were recorded using an excitation voltage of $10 \mathrm{mV}$ (peak to peak) and the frequency was changed from 
$100 \mathrm{kHz}$ to $0.01 \mathrm{~Hz}$, with impedance being measured at five frequencies per decade. All EIS data were measured sequentially in both the descending and ascending frequency directions.

\section{RESULTS AND DISCUSSION}

Electrochemical impedance spectroscopy (EIS) was used to study the nature of the processes that occur at the metal/passive film/solution interphase in the presence of sulfide, chloride, and thiosulfate and in mixtures of these species, but due to the limitation of space, we will present the results only for sulfide in short-term experiments, as an example. The EIS spectra for passive film on mild steel were measured over a wide range of frequency (typically $100 \mathrm{kHz}$ to $0.01 \mathrm{~Hz}$ ) as function of the formation potential across the passive range in saturated solution of $\mathrm{Ca}(\mathrm{OH})_{2}+\mathrm{NaOH}$ at $\mathrm{pH} 13.5$ in the presence of the above mentioned species. The impedance was measured after holding the potential constant for 20-24 hours, in order to ensure that the passive film exists in the quasi-steady state, as determined by the constancy of the current. Since the stability of the electrochemical system during the EIS measurements is critical to obtaining viable data, the quality of the EIS data was checked both experimentally and theoretically, with the latter being performed using the Kramers-Kronig transforms [7-9]. The data were checked experimentally by stepping the frequencies from high-to-low and then immediately back from low-to-high, with the impedance being measured at each step, to ascertain that the same values were obtained at equivalent frequencies in the two directions. If the system is in the steady state, which means that the thickness and current are independent of time, the impedance data should match in the two frequencies step directions.

Figure 3(a) shows the Nyquist plots for EIS data of the passive film formed on carbon steel in saturated solution of $\mathrm{Ca}(\mathrm{OH})_{2}+\mathrm{NaOH}$ in $\mathrm{pH} 13.5$ at $60^{\circ} \mathrm{C}$ at an applied film formation potential of $0.0 \mathrm{mV}(\mathrm{Hg} / \mathrm{HgO})$ as function of sulfide concentration. The passive film was formed after potentiostatic polarization for 20 hours (short term experiment). The impedance data were found to be correctly transformed according to the Kramer-Kronig integral transforms [7-9], demonstrating that the system conforms to the constraints of linear system theory. The form of the plots in Figure 3 is typical of those for passive metals, indicating the transport of defects and other charge carriers within the film (e.g. electrons and holes). For the lowest frequency sampled $(0.01 \mathrm{~Hz})$, the impedance clearly decreases with increasing sulfide concentration, showing that the sulfide is a depassivation species. In consequence, it is clear that sulfide catalyses the transfer of charge across the passive film.

Figure 3 (b), (c) and (d) demonstrate the use of the parameters obtained by optimization of the PDM on the experimental data, in which standard rate constants, $k_{i}^{0}$, polarizability, $\alpha$, transfer coefficients, $\alpha_{i}$, electric field, $\varepsilon$, and other parameters, were obtained. The optimized parameter values were then used, subsequently, to calculate the real and imaginary components of the impedance and the calculated values were compared directly with the experimental data. The experimental and calculated data plotted in Figures 3(a) and 3(b) are in good agreement, which instills considerable confidence that the parameter values may be used to estimate other important properties of the passive film, including its ability to protect the metal over extremely long exposure periods.

It was initially decided to perform long term experiments under oxic and anoxic conditions in simulated concrete pore water comprising saturated solutions of $\mathrm{Ca}(\mathrm{OH})_{2}+\mathrm{NaOH}$ with $\mathrm{pH}=13.5$ at $80{ }^{\circ} \mathrm{C}$. The objective of these experiments was to determine whether the passive current density for carbon steel changes over extended polarization periods (ranging in almost one year polarization time) from that observed in the short term experiments (ranging over 20-24 hours polarization time).

Figure 4 displays the open circuit potential data collected over a period of 343 days for low carbon steel tested under the above mentioned conditions. It is clear from Figure 4 that the steady state is not achieved over the experimental time and the potential drifts towards the noble direction as time goes on. This behavior is agreement with the predictions of the Point Defect Model (PDM) [2, 5], that the passive film is composed of a bilayer or multilayer structure, having a defective oxide adjacent to the metal surface (barrier layer) and an outer layer which formed from the hydrolysis of metal cations that 


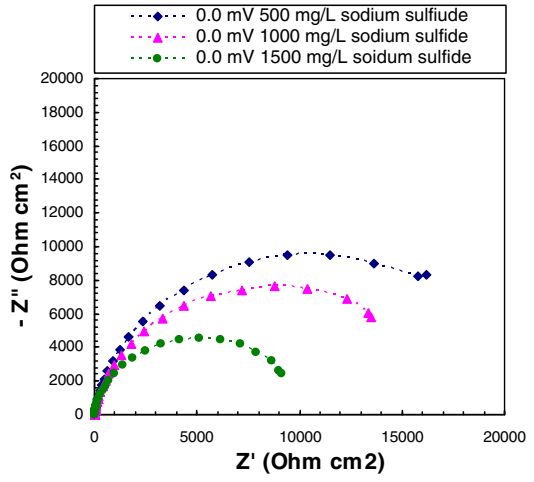

(a)
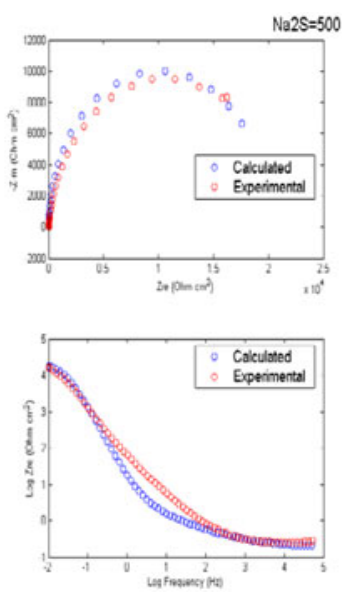

(c)

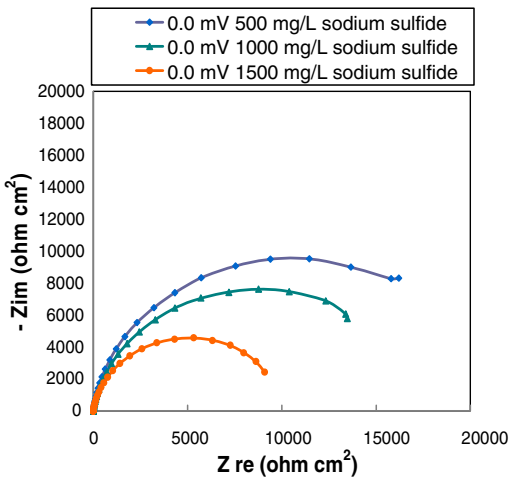

(b)
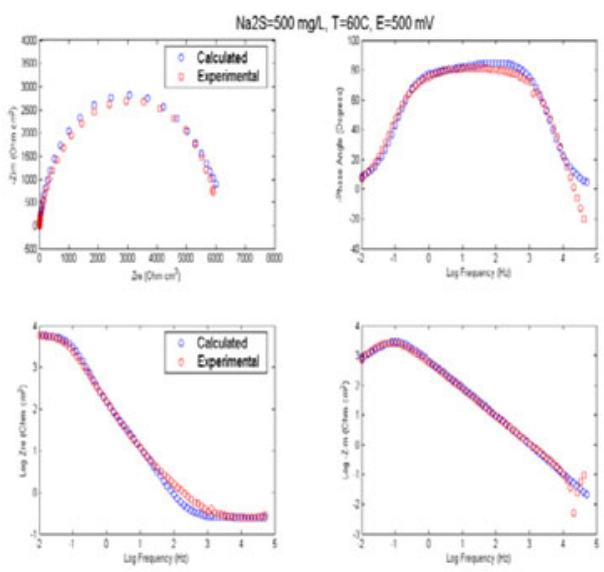

(d)

Figure 3. (a) Nyquist plots for passive film on carbon steel at $0.0 \mathrm{mV}(\mathrm{Hg} / \mathrm{HgO})$ as function of sulfide concentration at $60^{\circ} \mathrm{C}$. (b) Nyquist plots calculated from the optimized parameter values generated from the impedance data shown in Figure 3. (c) Optimized data of the Nyquist and Bode plots in Figure 3 under $0.0 \mathrm{mV}$ applied potential in $500 \mathrm{mg} / \mathrm{L}$ sodium sulfide, (d) at $500 \mathrm{mV}$ applied potential under the same conditions.

are ejected from the barrier layer into the solution. According to the PDM, the principal defects in the barrier layer are oxygen vacancies and/or cation interstitials. These defects yield n-type semiconductor behavior, which is found experimentally $[2,10,11]$.

Figure 5 shows the long term potentiostatic polarization curve for passive carbon steel in saturated $\mathrm{Ca}(\mathrm{OH})_{2}+\mathrm{NaOH}$ solution at $\mathrm{pH} 13.5$ at $80^{\circ} \mathrm{C}$, as function of applied potential over 343 days of polarization. The current transients are typical in form, in that the current density decreases approximately exponentially with time prior to attaining a steady state. Also to be noted is the increasing current density at $200 \mathrm{mV}$ and $0.0 \mathrm{mV}$, indicating the presence of metastable pitting events and/or crevices due to passivity breakdown occur under the prevailing conditions (in absence of any aggressive species). At some potentials e.g. $400 \mathrm{mV}(\mathrm{Hg} / \mathrm{HgO})$, the current density continues to decreases and may be as much as an order of magnitude lower than that indicated by the short term experiments. It is also remarkable in Figure 5 that the steady state current density does not depend strongly upon the applied film formation potential $[-200 \mathrm{mV}(\mathrm{Hg} / \mathrm{HgO})$ to $500 \mathrm{mV}(\mathrm{Hg} / \mathrm{HgO})]$, which is consistent with the diagnostic criteria obtained from the PDM for an n-type oxide film character $[2,10,11]$. 


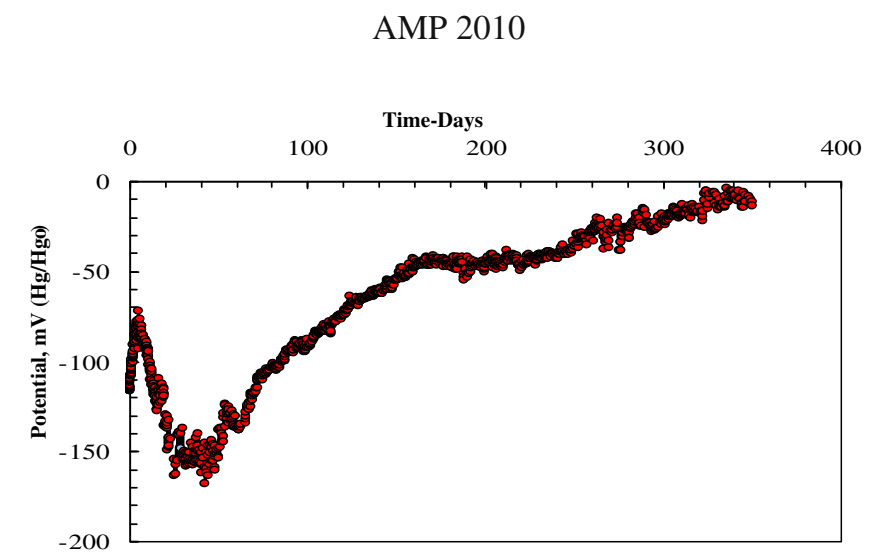

Figure 4. Open Circuit Potential at $80^{\circ} \mathrm{C}$ in saturated $\mathrm{Ca}(\mathrm{OH})_{2}+\mathrm{NaOH}$ solution at $\mathrm{pH} 13.5$ over 343 days.

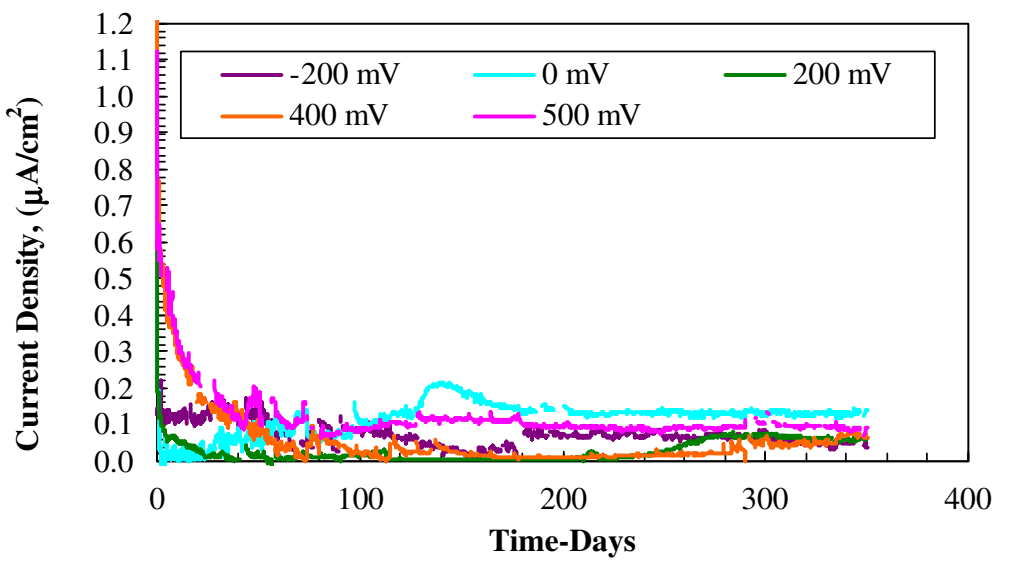

Figure 5. Long term potentiostatic polarization in saturated $\mathrm{Ca}(\mathrm{OH})_{2}+\mathrm{NaOH}$ in $\mathrm{pH} 13.5$ at $80^{\circ} \mathrm{C}$ after polarization period of 343 days. The indicated potentials are versus $\mathrm{Hg} / \mathrm{HgO}(2 \mathrm{M} \mathrm{NaOH})$.

Figures 6-8 show typical impedance spectra for the passive carbon steel in saturated solution of $\mathrm{Ca}(\mathrm{OH})_{2}+\mathrm{NaOH}$ in $\mathrm{pH} 13.5$ at $80{ }^{\circ} \mathrm{C}$ for different applied potentials and for several extended periods of time. These figures also compare the experimentally measured impedance and that calculated from the parameters values extracted from the PDM by optimization. It is remarkable that the measured impedance shows significant variation in the impedance magnitude with time during the entire length of the experiment, indicating that the impedance measurements appear to be sensitive to deviation from steady state conditions. For the potential of $-200 \mathrm{mV}(\mathrm{Hg} / \mathrm{HgO}, 2 \mathrm{M} \mathrm{NaOH})$, some changes in the impedance are observed over the first 30 days of the experiment; the Nyquist plot shows a smaller, initial value of the impedance at a fixed frequency, but after 56-days of exposure the impedance becomes much less dependent of time. These data suggest that significant modifications to the passive film occur over the long term, at times well beyond those employed in the short term experiments.

The research program outlined in this paper is continuing with the acquisition of electrochemical data for carbon steel in anoxic environments, which are postulated to exist after the initial oxic period of ca 300-1000 years. The principal tools include wide-band electrochemical impedance spectroscopy (EIS) and potentiostatic polarization, with the principal goals of measuring the passive current density and deriving values for the various parameters in the PDM. Additionally, upon the basis of the PDM, we have developed the theory to extrapolate the passive current density, corrosion potential, and passive film thickness to thousands of years into the future. This theory is entirely deterministic, takes into 


\section{EPJ Web of Conferences}

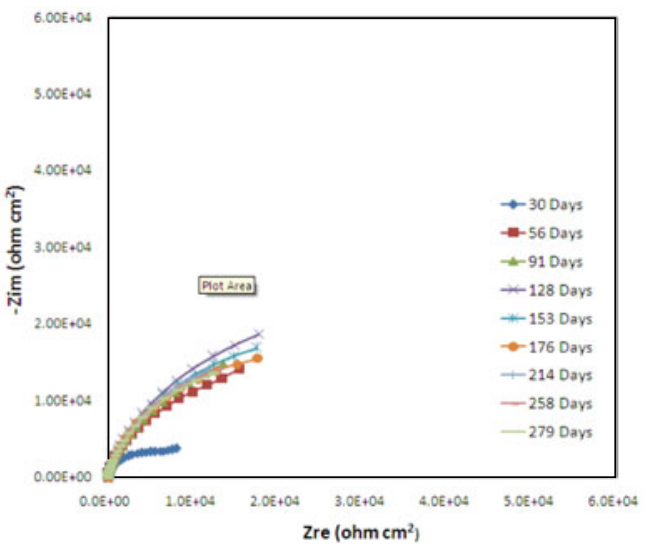

(a)

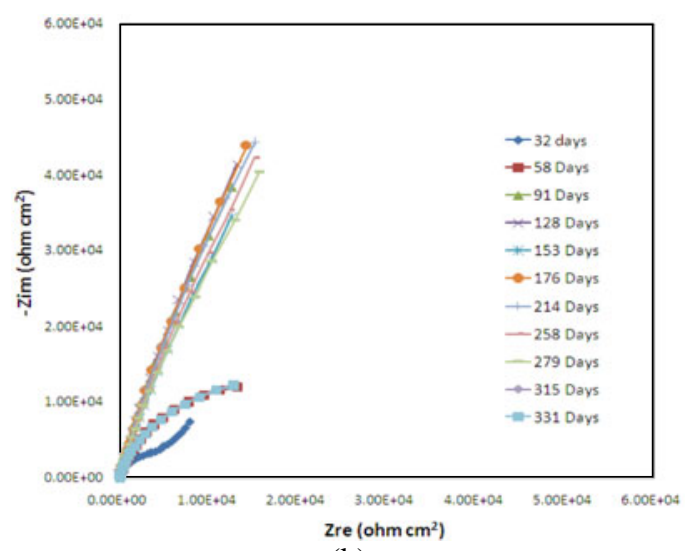

(b)

Figure 6. Nyquist impedance diagram calculated from the PDM using optimized model parameters (a) for passive carbon steel at $-200 \mathrm{mV}(\mathrm{Hg} / \mathrm{HgO})$ from 30 days up to 279 days of exposure. (b) at $200 \mathrm{mV}(\mathrm{Hg} / \mathrm{HgO})$ applied potential from 32 days up to 331 days.

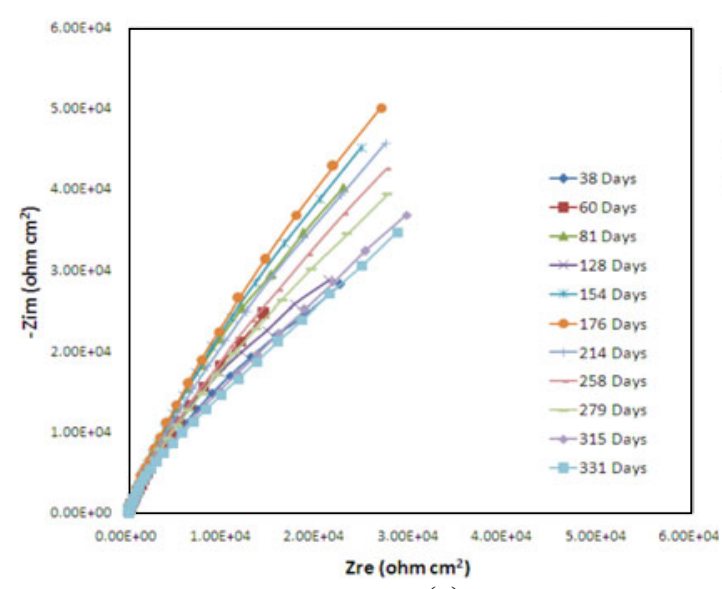

(a)
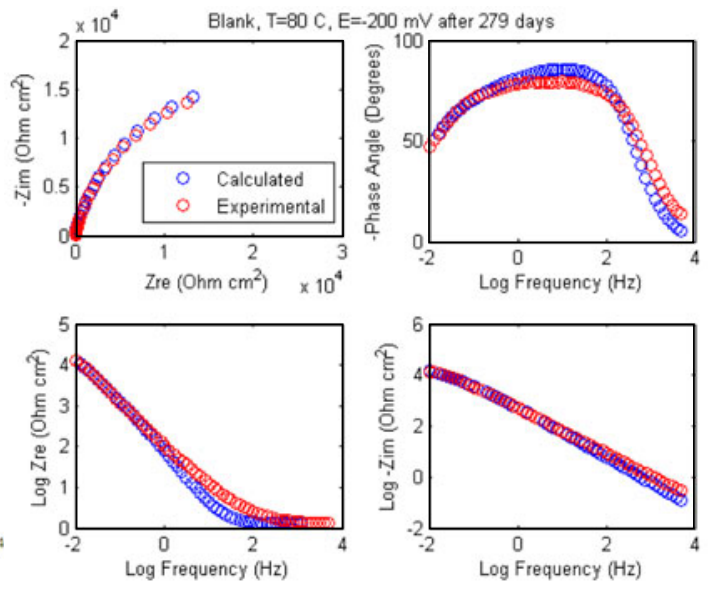

(b)

Figure 7. Nyquist impedance diagram calculated from the PDM using optimized parameters (a) for passive carbon steel at $500 \mathrm{mV}(\mathrm{Hg} / \mathrm{HgO})$ from 38 days up to 331 days and (b) Nyquist and Bode plots for passive carbon steel at $-200 \mathrm{mV}(\mathrm{Hg} / \mathrm{HgO})$ after 297 days, calculated from the PDM using optimized model parameters.

account the growth of the outer layer, and makes use of the PDM parameter values that are currently being determined by optimization of the bi-layer PDM on experimental EIS data.

Finally, this work was carried out to generate a database of values for the parameters contained within the PDM (see Table 1), in order that the model might be used to predict passive corrosion damage over HLNW repository horizons (typically 100,000 years). This ambitious goal raises an important question concerning the stability of the model parameters. In this regard, it is important to note that the PDM used in the analysis is a steady-state model and once steady state has been achieved the model parameter values are invariant with time. This does not mean that the model cannot account for corrosion of time-varying systems (e.g., as the repository cools), because those changes appear in the input parameters, not in the model parameters. Accordingly, we have every reason to expect that the model will provide high fidelity prediction to the far storage horizon. 

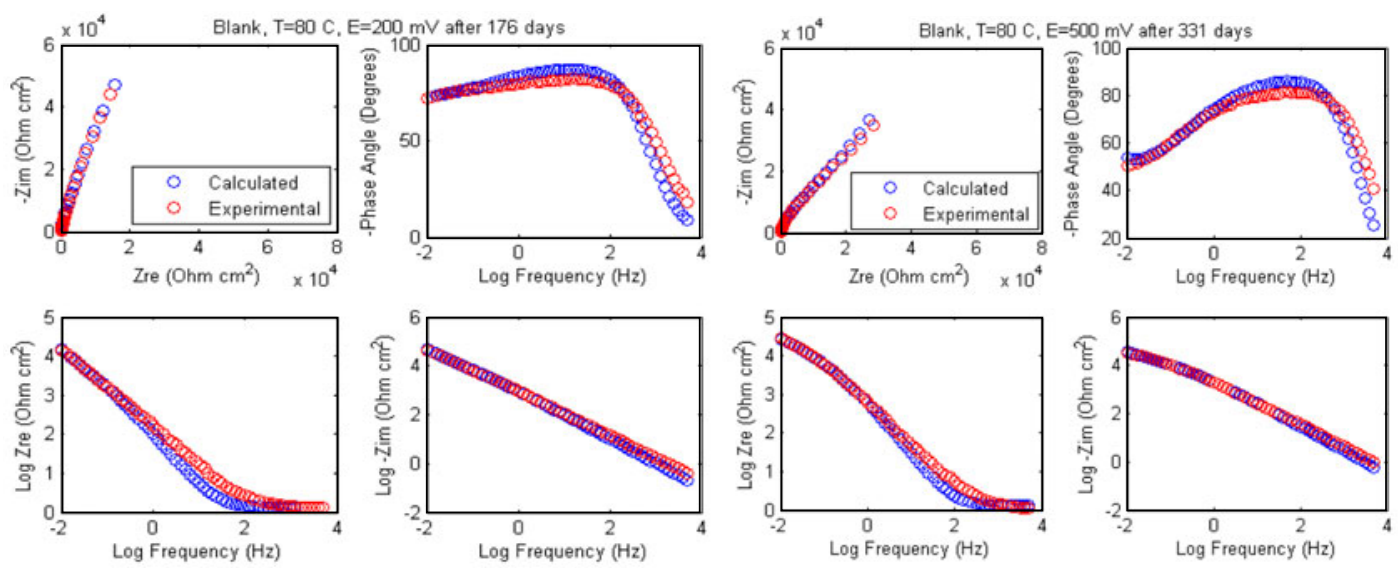

(a)

(b)

Figure 8. Nyquist and Bode plots calculated from the PDM using optimized parameters (a) for passive carbon steel at $200 \mathrm{mV}(\mathrm{Hg} / \mathrm{HgO})$ after 176 days and (b) at $500 \mathrm{mV}(\mathrm{Hg} / \mathrm{HgO})$ after 331 days.

\section{CONCLUSIONS}

The principal findings of this work may be summarized as follows:

- The passive current density has been measured potentiostatically in short term experiments after ca20- hours polarization and in long term experiments lasting more than 343 days.

- The short-term experiments indicated that the passive state on carbon steel attained a steady state after about 20 hours. However, the long-term experiments indicate that the current density continues to decrease and may be as much as an order of magnitude lower than that indicated by the short-term experiments. In particular, impedance measurements appear to be sensitive to deviation from the steady-state.

- The steady state current density is found to be independent of the passive film formation potential, which is consistent with the diagnostic criteria obtained from the PDM for an n-type oxide film character.

- The impedance of passive carbon steel decreases with increasing sulfide concentration from 0.0 to $1500 \mathrm{mg} / \mathrm{L}$ sodium sulfide at $60^{\circ} \mathrm{C}$.

- Optimization of the PDM on the experimental impedance data for the passive state yield a set of parameter values that can be used to predict the steady state and transient film formation kinetic process over very long exposure periods (film thickness and passive current density).

- The findings of this study are consistent with the predictions of the Point Defect Model.

\section{References}

[1] D. D. Macdonald, M. Urquidi-Macdonald, G. R. Engelhardt, O. Azizi, A. Saleh ${ }^{1}$, A. Almazooqi O. Rosas-Camacho, "Some Important Issues in the Electrochemistry of Carbon Steel in Simulated Concrete Pore Water: Part I. Theoretical Issues", Proc. $4^{\text {th }}$ International Workshop on Long-Term Prediction of Corrosion Damage in Nuclear Waste Systems, Conference Centre 'Oud Sint-Jan', Bruges, Belgium, June 28-July 2, (2010)

[2] D.D. Macdonald, Pure Appl. Chem., 71, 951 (1999)

[3] D.D. Macdonlad, A . Sun, Electrochemica Acta, 51, 1767-1779 (2006)

[4] S. Ahn, H. Kwon, D.D. Macdonald, J. Electrochem. Soc. 152, (11) B482-B490 (2005) 
[5] J. Ai, Y. Chen, M. Urquidi-Macdonald, D.D. Macdonald, J. Electrochem. Soc. 154, (1), C43-C51 (2007)

[6] J. Ai, Y. Chen, M Urquidi-Macdonald, D.D. Macdonald, J. Electrochem. Soc. 154, (1), C52-C59 (2007)

[7] M. Urquidi-Macdonald, S. Real, D.D. Macdonald. "Application of Kramers-Kronig Transforms in the Analysis of Electrochemical Impedance Data. II. Transformations in the Complex Plane". J. Electrochem. Soc., 133(10), 2018-2024 (1986)

[8] D. D. Macdonald "Some Advantages and Pitfalls of Electrochemical Impedance Spectroscopy". Corrosion, 46(3), 229-242 (1990)

[9] M. Urquidi-Macdonald, S. Real, D. D. Macdonald. "Application of Kramers-Kronig Transforms in the Analysis of Electrochemical Impedance Data. III. Stability, and Linearity". Electrochim. Acta, 35(10), 1559-1566 (1990)

[10] J. Liu, D. D. Macdonald, J. Electrochem. Soc., 148, B425 (2001)

[11] D. D. Macdonald, J. Electrochem. Soc., 139, 3434 (1992) 